\title{
Influence of wearing personalized high heels on the posture of women of different ages: A clinical cross-sectional study
}

Guido Schröder $^{*}$, Christina Dahms ${ }^{2}$, Raimond Boldt ${ }^{2}$, Marko Schulze ${ }^{3}$, Anne Hornung ${ }^{4}$, Verena Blaas ${ }^{5}$, Katrin Hesse ${ }^{1}$ and Hans-Christof Schober ${ }^{1}$

${ }^{1}$ Klinikum Südstadt, Südring 81, 18059 Rostock, Germany

${ }^{2}$ University of Rostock, 18057 Rostock, Germany

${ }^{3}$ Institute of Anatomy Rostock, University Medicine Rostock, Gertrudenstraße 9, 18057 Rostock, Germany

${ }^{4}$ Institute for Biostatistics and Informatics in Medicine and Ageing Research, University of Rostock, 18057 Rostock, Germany

${ }^{5}$ Institute for Forensic Medicine, University Medicine Rostock, St.-Georg-Straße. 108, 18055 Rostock, Germany

\begin{abstract}
Background: High heels are often worn by women, some of whom consider this style of shoes an important part of their gender identity. At the same time, many wearers experience pain in their feet, legs and back. The causes of the pain are complex and have not been identified conclusively. In hormonal causes, changes in posture are particularly relevant and the impact high heel shoes have on causing pain and affecting posture of different ages has not yet been examined.

Methods: One hundred forty women were recruited and retrospectively assigned to age groups: Group A: 18-25 years, Group B: 26-34 years, Group C: 35-49 years, Group D: 50-79 years. The kyphosis angle (ka), the lordosis angle (la) and the trunk inclination (ti) were determined as posture parameters. In addition, we assessed pain by using a questionnaire.

Results: 136 women (97 per cent) aged 18 to 79 years completed the study. The kyphosis angles ( $\mathrm{p}=0.023)$ and the lordosis angles ( $\mathrm{p}=0.016)$ were significant for the whole group. Within group $\mathrm{D}$, the kawas significant $(\mathrm{p}=0.030)$. Between the groups, the ka heel (A vs. C, p=0.006; A vs. D, p=0.004) and the heel height (A vs. D, $\mathrm{p}=0.001$; B vs. $\mathrm{D}, \mathrm{p}=0.006$ ) were statistically significant. The pain, while wearing high heels was significantly different between the groups ( $\mathrm{p}=0.039)$, with younger wearers being affected more frequently.

Conclusions: Wearing high heels is associated with a change in postural parameters, with younger women compensating for this by adjusting the lumbar spine, while older women react with a change in the thoracic spine. In both cases, the centre of gravity is balanced. The higher pain perception of younger women is presumably multifactorial. In particular, higher heels and a lack of experience in movement due to a lower frequency of wear should be mentioned.
\end{abstract}

\begin{abstract}
Abbreviations: BMI: Body Mass Index; cm: centimetre; et al.: et alia; kg: kilogram; ka: kyphosis angle; la: lordosis angle; NSAID: Nonsteroidal Anti-Inflammatory Drugs; No.: Number; NRS: Numerical Rating Scale; p: p-value; ti: trunk inclination; VRS: Video Raster Stereography; WHO: World Health Organization; ${ }^{\circ}$ : degree.
\end{abstract}

\section{Background}

An estimated 78 per cent of all women regularly wear high heels [1]. For many of these women it forms an important part of their gender identity [2]. At the same time, about 58 per cent [1] suffer from back pain $[1,3,4]$, the causes of this pain are complex and it has not been conclusively resolved. Some authors report an increase in static lumbar lordosis $[3,5,6]$ and other authors have observed decreased lumbar lordosis $[1,7,8]$. In addition, there are contradictory statements on the displacement of the gravitational line, the head posture and the pelvic inclination of women wearing high heels $[6,8-10]$. There is agreement, however, that wearing high heels is associated with increased strain on tendons, ligaments, joints and effects stability [1116]. Relaxin and estrogen, which initiate a loosening of the ligament connections especially during pregnancy, can cause additional injury in this context $[17,18]$. In the course of evolution, the female body has reacted to special changes in stress by adapting the back structure, among other things, and the lumbar spine is more strongly hollow- cross-shaped bent with women than with men [19]. In addition, three instead of two of the lower lumbar vertebrae are interlocked and thus reinforced and the distances between the vertebral joints are also larger. Shear forces occurring between the vertebrae are reduced as a result. Pregnant women can bend backwards to compensate for the increasing weight at the front without damaging their back [19]. It remains unclear why this mechanism fails when heels are worn.

\section{Methods}

The aim of this paper is to examine the influence of wearing personalized high heels on the posture of women of different ages. At the same time, statements about the associated pain will be evaluated.

\section{Study design and recruitment}

The study design corresponds to a monocentric, clinical examination of a treatment group in cross-sectional design. The

${ }^{\star}$ Correspondence to: Guido Schröder, Klinikum Südstadt, Südring 81, 18059 Rostock, Germany, Tel: +49 (0)381 - 44015000; E-mail: guido.schroeder1@gmx.net

Key words: women, high heels, body posture, back pain, biomechanic

Received: May 16, 2019; Accepted: June 04, 2019; Published: June 13, 2019 
recruitment of the test subjects was carried out by the Klinikum Südstadt Rostock and the University of Rostock. A flyer campaign also attracted female test subjects.

\section{Inclusion and exclusion criteria}

Exclusion criteria of the clinical examination were females under 18 , growth retardation, anatomical deformities of the spine, previous spinal surgery and psychiatric diseases. Participants who did not meet any of the exclusion criteria were included in the clinical trial.

\section{Test subjects}

The test persons were divided into four age groups, A-D. Group A included women aged 18 to 25 years (height $170.6 \pm 6.9 \mathrm{~cm}$, weight $66.6 \pm 9.5 \mathrm{~kg}$, Body Mass Index (BMI) $22.8 \pm 2.6$ ), group B included women aged 26 to 34 years (height $169.1 \pm 4.2 \mathrm{~cm}$, weight $69.4 \pm 15.8$ $\mathrm{kg}$, BMI $24.3 \pm 5.2$ ), group C included women aged 35 to 49 (size 167.1 $\pm 5.4 \mathrm{~cm}$, weight $67.7 \pm 13.4 \mathrm{~kg}$, BMI $24.3 \pm 4.6)$ and group D included women aged 50 to 79 (size $165.1 \pm 6.4 \mathrm{~cm}$, weight $66.4 \pm 10.5 \mathrm{~kg}$, BMI $24.3 \pm 3.6)$.

\section{Imaging examination methods - Video raster stereography (VRS)}

In order to document changes in the posture of the test subjects, we used the method of photogrammetric measurement of the back using raster stereography. A grid of parallel lines is projected onto the back surface of the test subjects and deformed by the body's own surface contour [20,21]. Each of the 81 transverse lines consists of light points (Figure 1) that are captured by a camera system [22]. In a medium sized person, 25000 measuring points are recorded initially and afterwards reduced by interpolation for reasons of smoothing and data reduction. This results in a homogeneous distribution of 8000 points with a depth resolution of $0.2 \mathrm{~mm}$ [23]. Via fixed points (Figure 1; spinous process symmetry line, vertebra prominens, left and right dimple, sacrum point) a reference system corresponding to the body is formed from space coordinates $(x, y, z)$. Triangulation automatically generates mathematical parameters for the calculation of the frontal and sagittal planes and for surface rotation. Accordingly, statements can be made about the kyphosis angle (in degree, ${ }^{\circ}$ ), the lordosis angle (in degree, $\left.{ }^{\circ}\right)$ and the forward leaning of the trunk (in degree, ${ }^{\circ}$ ) (Figure 1). The maximum kyphosis angle results from the surface tangent of the upper inflectional point cervicothoracic (ICT) at the vertebra prominens (VP) and the inflectional point thoracolumbar (ITL). The maximum lordosis angle describes the angle formed by the surface tangent as the points ITL and the inflectional point lumbosacral (ILS). The trunk inclination is the difference in height between VP and dimple middle (DM) related on the vertical plane (sagittal section) (Figure 1).

With the used DIERS formetric 4D system it took six seconds to record the back surface for the static analysis of the standing posture. Two pictures per second were generated, so in the end there were 12 pictures of the posterior trunk available for the measuring system. In order to define single shape parameters from the image series, an algorithm calculates averages from the complete scan. In line with the data reduction, the algorithm chooses one out of 12 images which is closest to the average results and reports these parameters to the spine scanner [24].

In the present investigation, three shots were taken while barefoot and three shots were taken while wearing high heels. These images were included in the evaluation. Taking into consideration that the sensation of being watched or to take part in an experiment might influence the participants behavior (Hawthorne-Effekt) [25] our approach was to obtain results most closely to the women's real body posture. The method of VRS was already applied in different studies [20,21,26-28] and achieved very good results for the intratester as well as the intratester reliability for ka, la and ti. So, this technique must be regarded as being liable to analyse the standing back. In this case the BMI has no influence on the reproducibility of the results [29].

Experience shows that in exceptional cases such as adipositas per magna, the successive standing of skin folds can result in nondetection of fixed points, which are crucial for the picture reconstruction and interpretation. Rasterstereography is a dependable method for a noninvasive and three-dimensional assessment of the spinal alignment in normal non-scoliotic individuals in the sagittal plane [30]. VRS can also help patients with scoliosis or other constitute deformities to record and monitor the disease progression [22,31-34]. Being free of ionising radiation might be the major advantage of VRS compared to radiological examinations $[23,33]$.

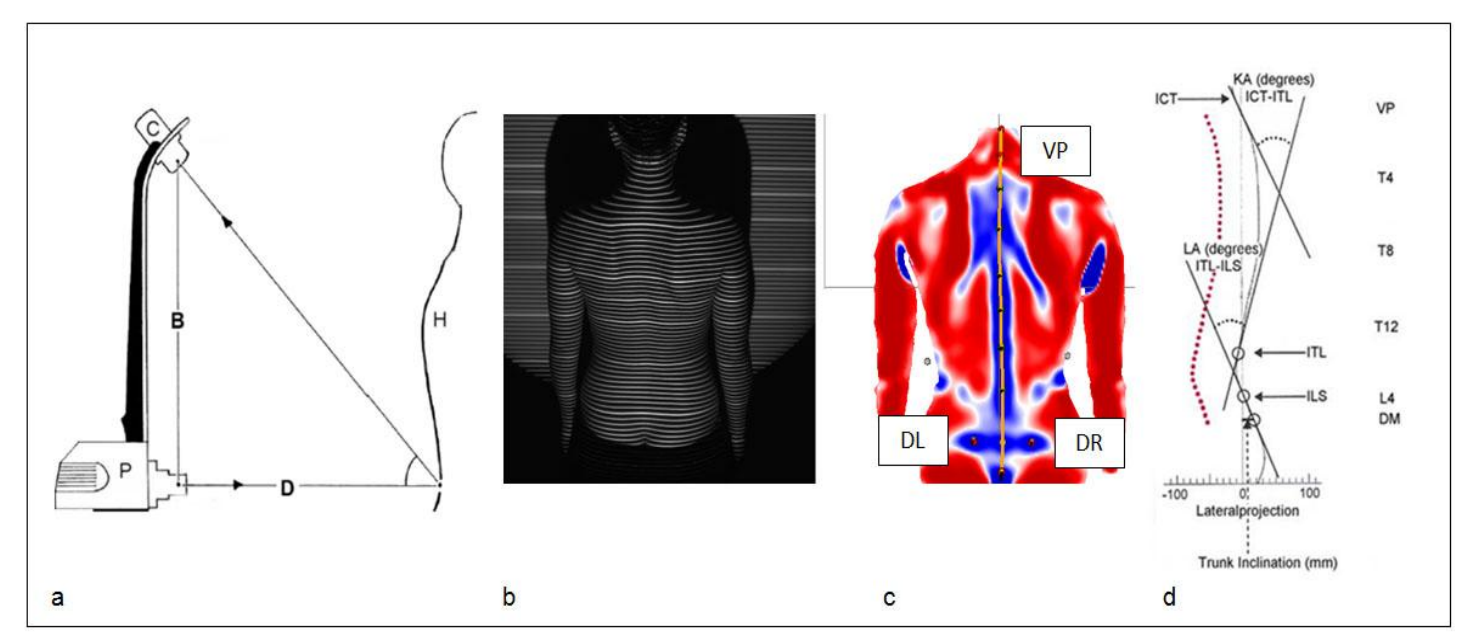

Figure 1. Schematic representation of the video raster stereography (according to Drerup), video camera (C), strip projector (P), human back surface (H), base distance (B) between camera and projector, distance (D) to the patient a; raster of parallel lines on the back surface b; surface modeling vertebra prominens (VP), dimple left (DL) and dimple right (DR) correspond to the left and right lumbar dimples c; Sagittal profile with kyphosis angle (KA), lordosis angle (LA), trunk inclination (TI), inflectional point cervicothoracic (ICT), inflectional point thoracolumbar (ITL), inflectional point lumbosacral (ILS), dimple middle (DM) correspond to kyphosis angle, lordosis angle, trunk inclination, turning points and lumbar pit center d 


\section{Heel height, plateau height, heel width}

We determined the heel height, plateau height and heel width with help of a ruler with a graduation of one tenth of a centimeter.

For the examination the women wore their personal footwear and preferred heel. The choice of using personal footwear resulted also from the age span of the study group. We assumed that older women would be more challenged to maintain their posture control in standardised or higher heels than younger women. The somatosensory changes coming with higher heels would have increased the risk of falling of older women $[35,36]$ and secondly, negative effects on sagittal posture parameters should be avoided.

The height of the heels without the platform height is classified as follows: flat heels up to $5 \mathrm{~cm}$, medium heels up to $7.5 \mathrm{~cm}$ and high heels $10 \mathrm{~cm}$ and over.

\section{Shoe types}

Following types of shoes were differentiated:

- Sandals - light and usually flat shoe made of straps or pierced leather

- Wedge heel - wide and straight shoe that uses most of the posterior foot section as a walking surface

- Pumps - wide cut or closed low shoes without tying and flat soles

- High heels - shoes with heels higher than $10 \mathrm{~cm}$ and over.

\section{Numerical rating scale}

The numerical rating scale (NRS) was used in the present clinical investigation. This is a one-dimensional pain scale based on 11 grades, where 0 means no pain and 10 means the strongest pain imaginable. Within this range, the subjects selected the number relating to their pain perception. The advantage of this system is the low error rate of the results and at the same time a high acceptance among the test persons [37].

\section{Statistics}

The collected data was analyzed with the statistical software package SPSS, version 23.0 (SPSS Inc., Chicago, USA). The first step involved a descriptive analysis. The quantitative characteristics were each described as mean, standard deviation, minimum, maximum, and number of observations available and were represented using the interval mean \pm standard deviation. Absolute and percentage frequencies specify the individual characteristics and their instances. Between the groups statistical comparisons for quantitative parameters have been realised by variance analysis and the Kruskal-Wallis test. For comparisons between the groups, the post hoc LSD test of the single factor variance analysis was used for more than two independent samples. When results in the Kruskal-Wallis test respectively the $\mathrm{Chi}^{2}$ test were statistically significant a Mann-Whitney-U test for pairwise comparisons was conducted. The selection was based on the result of the Kolmogorov-Smirnov test for normal distribution. The Kruskal Valais test was used in the case of non-existent normal distribution or the presence of an ordinal scale level. In addition, we used the dependent $\mathrm{t}$-test to evaluate changes in posture between measurement times. We used the $\mathrm{Chi}^{2}$ test to test qualitative characteristics and to analyze categorical frequencies. For statistically significant results in the Kruskal-Wallace and $\mathrm{Chi}^{2}$ tests, we also performed an analysis using the Mann- Whitney-U test between two independent samples. We then calculated the effect strength from the amount of the quotient of the test variable ( $\mathrm{z}$ ) and the root of the number of test subjects (n). A result value between 0.1 and 0.3 was considered weak, a value between 0.3 and 0.5 medium and a value greater than 0.5 strong. We performed a correlation analysis for individual parameters depending on the scale level. All p-values are the result of bilateral statistical tests and in principle $p \leq 0.05$ is considered statistically significant. An $\alpha$-adjustment was made for pair-by-pair tests, so that the significance level raised to $\mathrm{p} \leq 0.05 / 6$.

\section{Outcomes}

Test subjects and basic characteristics of the study population: Initially, 140 subjects took part in this clinical examination. Before the examination, one participant was excluded because she had undergone spinal surgery. During the VRS recordings, one subject experienced severe pain while standing on her heels, so that the recordings were incomplete and could not be evaluated. For another two participants, the VRS evaluation failed due to excessive BMI. The skin folds of this test person were placed so densely successively over each other that the scanner could not determine fixed points. The age of the participants in the study was 18 to 79 years $(35.7 \pm 13.0)$. One hundred and thirty-six of the 140 subjects ( 97.1 per cent) completed the clinical examination in full. The BMI were not different between age groups ( $p>0.05)$. With regard to the general anamnesis of back pain, there were no statistically significant differences between the age groups $(p>0.05)$ either in the question of whether back pain was present at all or in its frequency, intensity and localization. Overall, the test subjects reported that $56.4 \%$ of the pain occurred mainly in the lumbar region. The pain medication also did not differ significantly between the groups ( $p>0.05$ ). In total, $5.8 \%$ of the total group used World Health Organization (WHO) Level I painkillers, with nonsteroidal anti-inflammatory drugs (NSAIDs) accounting for $5.1 \%$ and paracetamol for $0.7 \%$. With regard to the question of musculoskeletal pre-existing conditions, there was a significant difference between the age groups $(\mathrm{p}=0.049)$. Especially in the group of women over 50, $45.5 \%$ already suffered from orthopaedic problems, while only $15 \%$ in the group of 18 to 25 year olds. Mainly age-related diseases, such as osteoporosis $(4.5 \%)$ or knee joint arthrosis $(9.1 \%)$ were found exclusively in the over 50 -year-old test subjects. The results of tasks demanding the back muscles showed a statistically significant difference between the groups $(\mathrm{p}=0.026)$. Particularly in the group of 26 - 34 and 35 - 49 year olds, $51.2 \%$ and $45.5 \%$ of participants respectively reported that they were engaged in activities such s moving patients or lifting children. There were no statistically significant differences between the age groups in terms of activity profile and sporting activity. With regard to the shoe characteristics of the test subjects, there were high or very significant differences between the groups with regard to the years of wearing $(\mathrm{p}<0.001)$ and the frequency of wearing high heels $(p=0.001)$. The comparison regarding heel height was also significant $(\mathrm{p}=0.006)$. In contrast, there were no statistically significant differences in shoe size, platform height, heel width and shoe type $(\mathrm{p}>0.05)$.

\section{Posture}

Baseline characteristics: The wearing of personalized high heels has an influence on the posture of the wearer. The adaptations differ depending on the age of the women (Table 1).

Total group: The results of the posture analysis show a statistically significant increase in $\mathrm{ka}\left(52.6^{\circ} \pm 9.1^{\circ}\right.$ vs. $\left.53.2^{\circ} \pm 8.6^{\circ}, \mathrm{p}=0.023\right)$. At the same time, there was a statistically significant reduction in la $\left(45.3^{\circ} \pm\right.$ $8.8^{\circ}$ vs. $\left.44.7^{\circ} \pm 9.0^{\circ}, \mathrm{p}=0.016\right)$. The ti, on the other hand, remained at the starting level ( $\mathrm{p}>0.05)$ (Table 2). 
Table 1. Basic characteristics of the study population

\begin{tabular}{|c|c|c|c|c|c|c|}
\hline General informations & $\begin{array}{c}\text { Overall group } \\
(\mathbf{n}=\mathbf{1 3 6}) \\
\mathbf{M} \pm \mathbf{S D}\end{array}$ & $\begin{array}{c}\text { Group A } \\
(n=40) \\
M \pm S D\end{array}$ & $\begin{array}{c}\text { Group B } \\
(n=41) \\
M \pm S D\end{array}$ & $\begin{array}{c}\text { Group C } \\
(\mathbf{n}=\mathbf{3 3}) \\
\mathbf{M} \pm \mathbf{S D}\end{array}$ & $\begin{array}{c}\text { Group D } \\
(n=22) \\
M \pm \text { SD }\end{array}$ & p-value \\
\hline Age (years) & $35.7 \pm 13.0$ & $23.4 \pm 1.5$ & $29.6 \pm 2.6$ & $43.5 \pm 4.7$ & $57.9 \pm 7.9$ & $<0.001^{\ominus}$ \\
\hline BMI $\left(\mathrm{kg} / \mathrm{m}^{2}\right)$ & $23.9 \pm 4.2$ & $22.8 \pm 2.6$ & $24.3 \pm 5.2$ & $24.3 \pm 4.6$ & $24.3 \pm 3.6$ & $0.465^{\ominus}$ \\
\hline \multicolumn{7}{|c|}{ General back pain anamnesis } \\
\hline yes/no (\%) & $69.1 / 30.9$ & $70 / 30$ & $68.3 / 31.7$ & $72.7 / 27.3$ & $63.6 / 36.4$ & $0.910^{\dagger \dagger}$ \\
\hline \multicolumn{7}{|l|}{ Frequency } \\
\hline daily (\%) & 16.2 & 2.5 & 17.1 & 21.2 & 31.8 & $0.588^{\ominus}$ \\
\hline occasionally (\%) & 52.9 & 67.5 & 51.2 & 51.5 & 31.8 & \\
\hline never $(\%)$ & 30.9 & 30.0 & 31.7 & 27.3 & 36.4 & \\
\hline \multicolumn{7}{|l|}{ Pain intensity } \\
\hline NRS (0 bis 10$)$ & $2.9 \pm 2.4$ & $2.3 \pm 1.8$ & $2.6 \pm 2.3$ & $3.6 \pm 2.7$ & $3.3 \pm 2.9$ & $0.133^{\ominus}$ \\
\hline \multicolumn{7}{|l|}{ Localisation } \\
\hline Cervical spine (\%) & 25.5 & 25.0 & 32.1 & 29.2 & 7.1 & $0.238^{\dagger \dagger}$ \\
\hline Thoracic spine (\%) & 9.6 & 17.9 & 10.7 & 0.0 & 7.1 & \\
\hline Lumbar spine (\%) & 56.4 & 53.6 & 53.6 & 54.2 & 71.4 & \\
\hline Whole back (\%) & 8.5 & 3.6 & 3.6 & 16.7 & 14.3 & \\
\hline \multicolumn{7}{|l|}{ Regular pain medication } \\
\hline yes/no $(\%)$ & $5.9 / 94.1$ & $0 / 100$ & $7.3 / 92.7$ & $6.1 / 93.9$ & $13.6 / 86.4$ & $0.169^{\dagger \dagger}$ \\
\hline \multicolumn{7}{|l|}{ Musculo skeletal diseases } \\
\hline Rheumatism yes/no (\%) & $5.1 / 94.9$ & $2.5 / 97.5$ & $0 / 100$ & $12.1 / 87.9$ & $9.1 / 90.9$ & $0.079^{\dagger \dagger}$ \\
\hline Orthopaedic yes/no(\%) & $23.5 / 76.5$ & $15 / 85$ & $19.5 / 80.5$ & $24.2 / 75.8$ & $45.5 / 54.5$ & $0.049^{\dagger \dagger}$ \\
\hline \multicolumn{7}{|l|}{ Activity profile } \\
\hline sitting $(\%)$ & 37.5 & 55.0 & 31.7 & 30.3 & 27.3 & $0.091^{\dagger \dagger}$ \\
\hline standing (\%) & 9.6 & 2.5 & 17.1 & 9.1 & 9.1 & \\
\hline mixed (\%) & 52.9 & 42.5 & 51.2 & 60.6 & 63.6 & \\
\hline \multicolumn{7}{|c|}{ Activities demanding the back muscles } \\
\hline yes/no(\%) & $39 / 61$ & $20 / 80$ & $51.2 / 48.8$ & $45.5 / 54.5$ & $40.9 / 59.1$ & $0.026^{\dagger \dagger}$ \\
\hline \multicolumn{7}{|l|}{ Sports activity } \\
\hline yes/no(\%) & $66.9 / 33.1$ & $75 / 25$ & $61 / 39$ & $54.5 / 45.5$ & $81.8 / 18.2$ & $0.097^{\dagger \dagger}$ \\
\hline \multicolumn{7}{|c|}{ Characteristics of the shoes } \\
\hline Shoesize (german) & $38.7 \pm 1.4$ & $38.8 \pm 1.6$ & $40.0 \pm 1.3$ & $38.8 \pm 1.2$ & $38.2 \pm 1.3$ & $0.161^{\ominus}$ \\
\hline Wearer (years) & $19.0 \pm 12.3$ & $8.1 \pm 2.4$ & $13.6 \pm 3.3$ & $25.0 \pm 5.3$ & $39.6 \pm 10.4$ & $<0.001^{\ominus}$ \\
\hline \multicolumn{7}{|l|}{ Frequency of wear } \\
\hline daily (\%) & 5.1 & 0.0 & 0.0 & 18.2 & 4.5 & $0.001^{\dagger \dagger}$ \\
\hline occasionally (\%) & 94.1 & 100.0 & 100.0 & 81.8 & 90.9 & \\
\hline Heel height $(\mathrm{cm})$ & $7.9 \pm 2.1$ & $8.4 \pm 2.1$ & $8.0 \pm 2.0$ & $7.9 \pm 2.1$ & $6.5 \pm 2.0$ & $0.006^{\pi}$ \\
\hline Plateau height $(\mathrm{cm})$ & $0.7 \pm 0.8$ & $0.7 \pm 0.7$ & $0.9 \pm 0.9$ & $0.7 \pm 0.8$ & $0.6 \pm 0.9$ & $0.692^{\ominus}$ \\
\hline Heel width $(\mathrm{cm})$ & $2.2 \pm 1.3$ & $2.0 \pm 1.2$ & $2.3 \pm 1.5$ & $2.3 \pm 1.2$ & $2.3 \pm 1.2$ & $0.516^{\ominus}$ \\
\hline \multicolumn{7}{|l|}{ Shoe type } \\
\hline Pumps (\%) & 39.0 & 37.5 & 31.7 & 39.4 & 54.5 & $0.568^{\dagger \dagger}$ \\
\hline High-heels (\%) & 33.1 & 42.5 & 36.6 & 27.3 & 18.2 & \\
\hline Cuban heels (\%) & 19.9 & 15 & 22.0 & 24.2 & 18.2 & \\
\hline Boota $(\%)$ & 4.4 & 5.0 & 4.9 & 6.1 & 0.0 & \\
\hline Sandal (\%) & 3.7 & 0.0 & 4.9 & 3.0 & 9.1 & \\
\hline
\end{tabular}

Data specified as mean \pm standard deviation and percentage of the corresponding group; ${ }^{\dagger \dagger}$ chi $^{2}$-test, ${ }^{\ominus}$ Kruskal-Wallace test, ${ }^{\pi}$ single factor variance analysis

Table 2. Results of the posture analysis of the overall group $(n=136)$

\begin{tabular}{|c|c|c|c|}
\hline Parameter & $\begin{array}{c}\text { barefoot } \\
\text { M } \pm \text { SD }\end{array}$ & heels \\
& $52.6 \pm 9.1$ & $53.2 \pm 8.6$ & \\
\hline Kyphosis angle (degree) & $45.3 \pm 8.8$ & $44.7 \pm 9.0$ \\
\hline Lordosis angle (degree) & $3.0 \pm 2.8$ & $2.8 \pm 3.0$ \\
\hline Trunk inclination (degree) & 0.023 \\
\hline
\end{tabular}

'paired t test 
Comparison within the age groups: The results of the posture analysis within the age groups (Table 3 ) show that a statistically significant increase in ka was only found in the age group of 50 to 79 -year-old subjects $\left(55.0^{\circ} \pm 11.1^{\circ}\right.$ vs. $\left.56.5^{\circ} \pm 9.2^{\circ}, p=0.030\right)$. In the age groups $\mathrm{A}$ to $\mathrm{C}$ there were no statistically relevant differences in this respect. With regard to la, changes in the sense of a steep position for age groups $\mathrm{A}$ and $\mathrm{B}$ are noticeable, which can be interpreted as a statistical trend $\left(\mathrm{A}: 43.6^{\circ} \pm 7.6^{\circ}\right.$ vs. $42.6^{\circ} \pm 8.0^{\circ}, \mathrm{p}=0.060 ; \mathrm{B}: 46.6^{\circ} \pm 9.1^{\circ}$ vs. $\left.46.0^{\circ} \pm 9.7^{\circ}, \mathrm{p}=0.069\right)$. Within the age groups $\mathrm{C}$ and $\mathrm{D}$, however, no statistically relevant differences were found for the la $(p>0.05)$.

When comparing the ti values within the age groups, there are also no statistically significant changes due to wearing high heels $(\mathrm{p}>0.05)$.

Comparison between age groups: The results of the posture analysis between the age groups (Table 4) showed no statically significant differences with regard to barefoot $\mathrm{ka}(\mathrm{p}>0.0083)$. When wearing high heels, there were significant differences for this parameter $\left(\mathrm{A}^{\circ}\right.$ vs. $\mathrm{C}^{\circ}$, $\mathrm{p}=0.006 ;$ A vs. $\mathrm{D}, \mathrm{p}=0.004$ ).
Looking at the collected values for ti, no statically significant differences were found for the barefoot parameters between age groups ( $p>0.0083$ ). With regard to the frequency of wear, significant differences between the groups $\left(\mathrm{A}^{\circ}\right.$ vs. $\mathrm{C}^{\circ}, \mathrm{p}=0.005$; $\mathrm{B}$ vs. $\left.\mathrm{C}, \mathrm{p}=0.005\right)$ could be determined. Equally, the comparison between the group $\mathrm{A}^{\circ}$ vs. $\mathrm{B}^{\circ}$ with regard to the activities that exercise the back musculature $(p=0.004)$. The effect level for these comparisons was intermediate (Table 4).

Sales level between the age groups: The test subjects put on the high heels which they used most frequently. In the age group of 18 to 25-year-old women, the average heel height of $8.4 \pm 2.1 \mathrm{~cm}$ was above that of the comparison groups. For women aged between 26 and 34 years, the heel height was $8.0 \pm 2.0 \mathrm{~cm}$. We found a similar value of 7.9 $\pm 2.1 \mathrm{~cm}$ in the age group of 35 to 49 -year-old women. In contrast, in the age group of 50 to 79 -year-old there was a clear difference in height $(\mathrm{p}=0.006)$, insofar as the average heel height in this group was $6.5 \pm$ $2.0 \mathrm{~cm}$ (Table 1). The comparison between groups showed significant

Table 3. Results of the posture analysis within the age groups

\begin{tabular}{|c|c|c|c|}
\hline Age group: years (number) & $\begin{array}{c}\text { Kw (degree) barefoot } \\
M \pm \text { SD }\end{array}$ & $\begin{array}{c}\text { Kw (degree) heel } \\
M \pm \text { SD }\end{array}$ & p-value ${ }^{\dagger}$ \\
\hline A: $18-25(n=40)$ & $49.6 \pm 7.3$ & $50.0 \pm 6.6$ & 0.536 \\
\hline$B: 26-34(n=41)$ & $52.4 \pm 9.5$ & $52.8 \pm 9.5$ & 0.353 \\
\hline$C: 35-49(n=33)$ & $54.9 \pm 8.3$ & $55.5 \pm 8.2$ & 0.293 \\
\hline$D: 50-79(n=22)$ & $55.0 \pm 11.1$ & $56.5 \pm 9.2$ & 0.030 \\
\hline Age group: years (number) & $\begin{array}{c}\text { Lw (degree) Barfuß } \\
\text { M } \pm \text { SD }\end{array}$ & $\begin{array}{c}\text { Lw (degree) Absatz } \\
\mathbf{M} \pm \text { SD }\end{array}$ & p-value ${ }^{\dagger}$ \\
\hline A: $18-25(n=40)$ & $43.6 \pm 7.6$ & $42.6 \pm 8.0$ & 0.060 \\
\hline$B: 26-34(n=41)$ & $46.6 \pm 9.1$ & $46.0 \pm 9.7$ & 0.069 \\
\hline$C: 35-49(n=33)$ & $46.6 \pm 9.1$ & $46.5 \pm 8.0$ & 0.758 \\
\hline$D: 50-79(n=22)$ & $43.9 \pm 9.6$ & $43.5 \pm 10.1$ & 0.450 \\
\hline Age group: years (number) & $\begin{array}{c}\text { Rn (degree) Barfuß } \\
\qquad \begin{array}{l}M \\
\text { SD }\end{array}\end{array}$ & $\begin{array}{c}\text { Rn (degree) Absatz } \\
\text { M } \pm \text { SD }\end{array}$ & p-value ${ }^{\dagger}$ \\
\hline A: $18-25(n=40)$ & $2.4 \pm 2.5$ & $2.3 \pm 2.5$ & 0.660 \\
\hline$B: 26-34(n=41)$ & $2.5 \pm 2.9$ & $2.5 \pm 3.2$ & 0.900 \\
\hline$C: 35-49(n=33)$ & $3.4 \pm 2.6$ & $3.2 \pm 2.9$ & 0.337 \\
\hline $\mathrm{D}: 50-79(\mathrm{n}=22)$ & $4.3 \pm 2.9$ & $3.9 \pm 3.3$ & 0.156 \\
\hline
\end{tabular}

paired t test, Kw: Kyphosis angle, Lw: Lordosis angle, Rn: Trunk inclination

Table 4. Results of the age groups

\begin{tabular}{|c|c|c|c|}
\hline Parameter & Group & p-value & Effect size \\
\hline \multicolumn{4}{|l|}{ Posture } \\
\hline \multirow{2}{*}{ Ka barefoot (degree) } & A vs. C & $0.013^{\pi}$ & ------- \\
\hline & A vs. D & $0.026^{\pi}$ & ------- \\
\hline \multirow{3}{*}{ Ka heels (degree) } & A vs. C & $0.006^{\pi}$ & ------- \\
\hline & A vs. D & $0.004^{\pi}$ & ------- \\
\hline & B vs. D & $0.093^{\pi}$ & ------- \\
\hline \multirow{2}{*}{ Ti barefoot (degree) } & A vs. D & $0.009^{\pi}$ & ------- \\
\hline & B vs. D & $0.011^{\pi}$ & ------ \\
\hline \multirow[t]{2}{*}{ Orthopaedic illnesses } & A vs. D & $0.009^{\mu}$ & ------ \\
\hline & B vs. D & $0.031^{\mu}$ & -------- \\
\hline \multirow[t]{3}{*}{ Activities demanding the back muscles } & A vs. B & $0.004^{\mu}$ & 0.324 \\
\hline & A vs. C & $0.021^{\mathrm{M}}$ & ------- \\
\hline & A vs. D & $0.080^{\mathrm{\mu}}$ & -------- \\
\hline \multirow[t]{2}{*}{ Frequency of wear } & A vs. C & $0.005^{\mathrm{M}}$ & 0.327 \\
\hline & B vs. C & $0.005^{\mu}$ & 0.329 \\
\hline \multirow[t]{3}{*}{ Heel height $(\mathrm{cm})$} & A vs. D & $0.001^{\pi}$ & ------- \\
\hline & B vs. D & $0.006^{\pi}$ & ------ \\
\hline & C vs. D & $0.010^{\pi}$ & ------- \\
\hline
\end{tabular}

${ }^{\pi}$ Post-hoc LSD test (single factor variance analysis), ${ }^{M}$ Mann-Whitney-U test 
differences $\left(\mathrm{A}^{\circ}\right.$ vs. $\mathrm{D}^{\circ}, \mathrm{p}=0.001 ; \mathrm{B}$ vs. $\left.\mathrm{D}, \mathrm{p}=0.006\right)$. An overview of the values collected and a comparison between the groups can be found in Table 4.

Pain while wearing high heels: In the whole group, 57.4\% reported pain while wearing high heels. The comparison between the groups showed a significant difference $(\mathrm{p}=0.046)$. In addition, the comparison between the age groups showed a significant difference in pain localization ( $\mathrm{p}=0.039$ ). Approximately $60 \%$ of subjects in age groups $\mathrm{A}$ and $\mathrm{B}$ experienced pain in the area of the feet, while $33.3 \%$ of age group C and $22.7 \%$ of age group D reported pain in this area. Overall, the feet were the most frequently affected part of the body with $47.8 \%$ reporting pain. Among the test subjects over 50, it was noticeable that the buttocks and legs were each named with $13.6 \%$, with the back playing a subordinate role here as a source of pain. In contrast, $4.9 \%$ of age group B and $6.1 \%$ of age group $C$ reported pain in this area. An overview of the values collected can be found in Table 5 .

A correlation analysis according to Pearson between the indicated pain level of the NRS and the heel height was not statically significant $(\mathrm{p}>0.05)$. In contrast, the correlation analysis using the $\mathrm{Chi}^{2}$ test between divided heel height and pain while wearing high heels showed a statistically significant value ( $\mathrm{p}=0.003)$. In total, $77.3 \%$ of the subjects wearing high heels between 7.5 and $10 \mathrm{~cm}$ and $77.8 \%$ of those with heels higher than $10 \mathrm{~cm}$ reported pain while wearing heels. Also significant were the contingency coefficient and Cramer's V ( $p=0.016)$ with respect to the correlation between the frequency of wearing high heels and pain while wearing them.

\section{Discussion}

For the first time, the present study allows a comparison of the effects of wearing high heels on the posture of women of different ages. In this context, our results show that when looking at the group as a whole, the subjects significantly change their ka (kyphosis) and la, while the trunk inclination remains almost unchanged. Consequently, the centre of gravity of the body is balanced independently of the heel height, which corresponds as far as possible to the data already published. Bendix et al. [7] report that with increasing heel height the lumbar lordosis and the pelvic tilt decrease with constant gravity line and activity of the back and abdominal muscles. Opila et al. [8] also observed a flattening of the lumbar spine in their test subjects. It showed that older test subjects between 50 and 79 years of age react to an increase in heel height with an increase in the ka and the la, remained unchanged. Younger wearers, on the other hand, tend to compensate for the increase in heel height with a steep position of the pelvis or a decrease in the la and the ka remained unchanged. Remarkably, the tendency towards the trunk remains at a constant level despite heel height in all age groups. The question is what processes are causing this effect? It is conceivable that the mobility of the spine may be restricted by the natural aging process, so that older test subjects find it easier to achieve the body's centre of gravity by adjusting the ka. Butler et al. [38] were able to show that degenerative changes in the discus intervertebralis already occur in the third decade of life, while the vertebral joints are affected by corresponding changes only one to two decades later. It can also be assumed that posture was influenced by osteoporosis, reduced muscle mass and prolapsed intervertebral discs in the age group of women over $50[39,40]$. In contrast, Dai et al. [3] report that an increase in heel height worn by very young women causes an increase in the ka and la. At the same time, the line of gravity shifted significantly to ventral. Oliveira Pezzan and colleagues [6] also assume that the la increases after completion of their study, observing this effect in inexperienced wearers of high heels. Experienced wearers, on the other hand, reacted by reducing the la.

Baaklini et al. [1] proved with their study that inexperienced people wearing high heels have a lower thoracic curvature angle than those wearing low heels. In addition, they found that regardless of their experience in wearing shoes with heels, women wearing significant heels showed lower maximum and minimum lumbar and thoracic curvature angles than those in barefeet. The authors therefore assume that lower back pain may be associated with factors other than wearing high heels alone.

Overall, it can be stated that the research results are very heterogeneous and that a final clarification has not yet been possible. In general, it can be observed that heel elevation limits stamina and functional mobility [41]. The question that arises is what influence does experience in wearing high heels and the frequency of wearing high heels have on posture.

Iunes et al. [9] conclude that neither the frequency of wearing nor the shoe type have an influence on the static posture. In the present study, the type of footwear was also not different between the groups. The test subjects put on the high heels they wore most frequently. Accordingly, it can be assumed that the motor adaptation phase was already completed in all age groups at the beginning of the study. The difference with regard to the years of wear generally gives little information about the actual wearing behaviour. Because of this, we specifically documented the frequency of wearing high heels. This was significantly higher in the age group of 35 to 49 -year-old test subjects than in the younger age groups. At the same time, the posture analysis in this age group showed no difference in $\mathrm{ka}$, la and ti due to wearing high heels. Accordingly, frequent wearing of high heels leads to less pronounced changes in posture.

Overall, subjects reported more frequent pain when they rarely wore high heels. We therefore assume that the frequency of wearing high heels also has an effect on pain perception. At the same time the assumption exists that the heel height can have an influence. Hong et al. [42] report that higher heels significantly limit the feeling of comfort and biomechanics, while the latter starts directly at the foot due to the heel elevation. In their review, Wiedemeijer and Otten [5] assume that an increase in plantar flexion results in an increase in knee flexion. The knee must compensate the loss of strength production in the ankle joint by increasing its own strength production. At the same time, an increased knee flexion improves shock absorption, which is partially lost in the ankle joint. Increased knee flexion allows early loading of the

Table 5. Pain when wearing heels

\begin{tabular}{|c|c|c|c|c|c|}
\hline Parameter & $\begin{array}{c}\text { Overall group } \\
(\mathrm{n}=136)\end{array}$ & $\begin{array}{c}\text { Group A } \\
(\mathrm{n}=40)\end{array}$ & $\begin{array}{c}\text { Group B } \\
(\mathrm{n}=41)\end{array}$ & $\begin{array}{c}\text { Group C } \\
(\mathrm{n}=33)\end{array}$ & 6.1 \\
\hline Back (\%) & 3.7 & 2.5 & 4.9 & 9.1 & 0.0 \\
\hline Bottom and legs (\%) & 5.9 & 2.5 & 2.4 & 33.3 & $0.039^{\dagger \dagger}$ \\
\hline Feet (\%) & 47.8 & 60.0 & 61.0 & 13.6 \\
\hline None (\%) & 42.6 & 35.0 & 31.7 & 51.5 \\
\hline
\end{tabular}

Data specified as percentage of the overall group and percentage within the age groups, ${ }^{\dagger} \mathrm{Chi}^{2}$ test 
forefoot, which improves balance and, according to the authors, also causes anterior pelvic tilt, which in turn increases lordosis and lumbar muscle activity. However, these results refer to the gait with high heels, i.e. a dynamic situation, and can only be compared to a limited extent with the available static surveys, but they provide valuable insights into the interaction of the kinematic chain. In the static setting, lumbar flexion, as described above, tended to be lower in age groups A and B, whereas it did not change in age groups $\mathrm{C}$ and $\mathrm{D}$. The lumbar flexion of the lumbar spine was not affected in the static setting. Overall, the ti within the groups remained at the same level. Accordingly, it can be assumed that there was no significant increase in muscle activity, which was not investigated in the present study. Interestingly, it is mainly younger test subjects in age groups A and B who complain about pain in their feet, which can intensify over the years. Menz and colleagues [43] investigated the relationships between heel height, toe contour, foot pain and hallux valgus and concluded that wearing tight shoes at the age of 20 to 39 years can be decisive for the development of hallux valgus in later life. In their review, Barnish and Barnish [44] assume that wearing high heels is also associated with musculoskeletal pain and first-party injuries. Considering the importance of high heel shoes for the female gender identity described above and their widespread use as a fashion accessory, it seems difficult for many women to imagine a complete renunciation of wearing these shoes. Not least, the fact that wearing high heels for women goes hand in hand with psychosexual advantages which makes this special footwear a cultural entity that is difficult to grasp rationally [2].

In order to provide relief for women who decide to wear high heels despite the problems described, the use of inner soles offers the possibility of improving wearing comfort [42]. For older women, shoes with non-slip soles and low heels are also suitable to counteract the risk of falls [36].

All in all, however, further studies must follow in order to evaluate the long-term effects of wearing heels on posture.

\section{Limitations}

The cross-sectional design and the limited group size, especially within the age groups, are limitations of the present study. In addition, the missing normal distribution of some parameters is to be mentioned. More complex statistical methods could not be applied, so that the available results cannot be generalised easily. The posture is interindividually different and is also subject to daily fluctuations. A measurement at the same time of day was not logistically feasible. Furthermore, the lack of blinding of both the test person and the investigator should be mentioned as a further limitation.

\section{Conclusions}

Wearing heels leads to age-specific posture adjustments.

Younger wearers between 18 and 34 years tend to compensate for increased heel height by flattening the lumbar lordosis while older wearers between 50 and 79 years react with an increase in thoracic kyphosis.

Irrespective of the increase in heel height, the body's centre of gravity is always balanced.

Frequent wearing of high heel shoes is associated with less change in posture and reduced perception of pain.

\section{Declaration}

\section{Ethical approval}

We declare that this study with human subjects is in accordance with the Helsinki Declaration of 1975 as amended in 2000 and that it has been approved by the competent institutional ethics committee of the University of Rostock (Trial registration No. A 2018-0095, Registered 30. Mai 2018 - Prospectively registered).

\section{Consent to participate}

All subjects were informed comprehensively about the methods, purposes and risks of the study protocol and also received a written declaration of informed consent.

\section{Consent for publication}

$\mathrm{CD}$ agreed in writing to the publication of the illustration.

\section{Availability of data and material}

The vote of the Ethics Committee can be found at the following address (https://www.ethik.med.uni-rostock.de/ A 2018-0095). The consent to the publication of the photographic material has been given to the journal.

\section{Competing interests}

We certify that there is no competing of interests with any financial organization regarding the material discussed in the manuscript. All authors in this study declare that they have no competing interests.

\section{Funding}

There was no funding.

\section{Trial registration}

The clinical investigation was reviewed by the Ethics Committee of the University of Rostock and approved on 30.05.2018 (A 2018-0095).

\section{Authors' contributions}

HCS led the investigation and is co-responsible for the clinical trial concept. He also participated in the recruitment of the test subjects. GS organized the cooperation with the company DIERS ${ }^{\circledR}$ and designed the data preparation concept. CD carried out the survey, measurement and documentation of the data. She also participated in the recruitment of the test subjects. RB participated in the data preparation and correction of the typesetting. VB was responsible for the translation of the journal article and the recruitment of the test subjects. AH carried out the statistical data evaluation. MS and $\mathrm{KH}$ participated in the recruitment of the subjects.

\section{Acknowledgments}

The clinical examination was supported by the company DIERS ${ }^{\circledR}$, who provided the spinal scanner, for the period of data collection. But we declared that the supporters did not do any role in the study design, in the collection, analysis, and interpretation of data; in the writing of the manuscript; and in the decision to submit the manuscript for publication.

\section{References}

1. Baaklini E, Angst M, Schellenberg F, Hitz M, Schmid S, et al. (2017) High-heeled walking decreases lumbar lordosis. Gait Posture 55: 12-14. [Crossref] 
2. Barnish M, Morgan HM, Barnish J (2017) The 2016 high heels: Health effects and psychosexual benefits (HIGH HABITS) study: Systematic review of reviews and additional primary studies. BMC Public Health 18: 37.

3. Dai M, Li X, Zhou X, Hu Y, Luo Q, et al. (2015) High-heeled-related alterations in the static sagittal profile of the spino-pelvic structure in young women. Eur Spine J 24: $1274-1281$.

4. Mika A, Oleksy L, Mika P, Marchewka A, Clark BC (2012) The effect of walking in high- and low-heeled shoes on erector spinae activity and pelvis kinematics during gait. Am J Phys Med Rehabil 91: 425-434. [Crossref]

5. Wiedemeijer MM, Otten E (2018) Effects of high heeled shoes on gait. A review. Gait Posture 61: 423-430. [Crossref]

6. Oliveira Pezzan PA de, Joao SMA, Ribeiro AP, Manfio EF (2011) Postural assessment of lumbar lordosis and pelvic alignment angles in adolescent users and nonusers of high-heeled shoes. J Manipulative Physiol Ther 34: 614-621.

7. Bendix T, Sørensen SS, Klausen K (1984) Lumbar curve, trunk muscles, and line of gravity with different heel heights. Spine (Phila Pa 1976) 9: 223-227. [Crossref]

8. Opila KA, Wagner SS, Schiowitz S, Chen J (1988) Postural alignment in barefoot and high-heeled stance. Spine (Phila Pa 1976) 13: 542-547. [Crossref]

9. Iunes DH, Monte-Raso W, Santos CB, Castro FA, Salgado HS (2008) Postural influence of high heels among adult women: analysis by computerized photogrammetry. Rev Bras Fisioter 12: 454-459.

10. Silva AM, Siqueira GR de, da Silva GAP (2013) Implications of high-heeled shoes on body posture of adolescents. Rev Paul Pediatr 31:265-271.

11. Moore JX, Lambert B, Jenkins GP, McGwin G (2015) Epidemiology of high-heel shoe injuries in U.S women: 2002 to 2012. J Foot Ankle Surg 54: 615-619.

12. Titchenal MR, Asay JL, Favre J, Andriacchi TP, Chu CR (2015) Effects of high heel wear and increased weight on the knee during walking. J Orthop Res 33:405-411.

13. Zollner AM, Pok JM, McWalter EJ, Gold GE, Kuhl E (2015) On high heels and short muscles: A multiscale model for sarcomere loss in the gastrocnemius muscle. $J$ Theor Biol 365: 301-310

14. Cronin NJ (2014) The effects of high heeled shoes on female gait: A review. $J$ Electromyogr Kinesiol 24: 258-263.

15. Gerber SB, Costa RV, Grecco LAC, Pasini H, Marconi NF, et al. (2012) Interference of high-heeled shoes in static balance among young women. Hum Mov Sci 31: 1247-1252.

16. Mika A, Oleksy L, Kielnar R, Swierczek M (2016) The influence of high- and lowheeled shoes on balance in young women. Acta Bioeng Biomech 18: 97-103.

17. Artal R (2016) Exercise in pregnancy: Guidelines. Clin Obstet Gynecol 59: 639-644.

18. Hartmann S, Bung P (1999) Physical exercise during pregnancy--physiological considerations and recommendations. J Perinat Med 27: 204-15.

19. Whitcome KK, Shapiro LJ, Lieberman DE (2007) Fetal load and the evolution of lumbar lordosis in bipedal hominins. Nature 450: 1075-1078.

20. Schröder G, Knauerhase A, Willenberg HS, Kundt G, Wendig D, et al. (2017) Biomechanics of the osteoporotic spine, pain, and principles of training. Arch Orthop Trauma Surg 137: 617-624.

21. Schröder G, Kundt G, Otte M, Wendig D, Schober H-C (2016) Impact of pregnancy on back pain and body posture in women. J Phys Ther Sci 28: 1199-1207.

22. Drerup B, Hierholzer E (1994) Back shape measurement using video rasterstereography and three-dimensional reconstruction of spinal shape. Clin Biomech 9: 28-36.

23. Drerup B (2014) Rasterstereographic measurement of scoliotic deformity. Scoliosis 9 : 20-22.

24. Degenhardt B, Starks Z, Bhatia S, Franklin GA (2017) Appraisal of the DIERS method for calculating postural measurements: An observational study. Scoliosis Spinal Disord 12: 28 .
25. Schwartz D, Fischhoff B, Krishnamurti T, Sowell F (2013) The Hawthorne effect and energy awareness. Proc Natl Acad Sci U S A 110: 15242-15246.

26. Schröder G, Knauerhase A, Kundt G, Schober HC (2014) Trunk stabilization with sling training in osteoporosis patients - a randomized clinical trial. Eur Rev Aging Phys Act 11: 61-68.

27. Schröder J, Stiller T, Mattes K (2011) Reference data in spine form analysis: Approximation to a majority norm and deviations in non-specific back pain syndromes. Manuelle Medizin 49: 161-166.

28. Yang DJ, Park SK, Kim JH, Heo JW, Lee YS, et al. (2015) Effect of changes in postural alignment on foot pressure and walking ability of stroke patients. J Phys Ther Sci 27: 2943-2945

29. Mohokum M, Mendoza S, Udo W, Sitter H, Paletta JR, et al. (2010) Reproducibility of rasterstereography for kyphotic and lordotic angles, trunk length, and trunk inclination: A reliability study. Spine 35: 1353-1358.

30. Schroeder J, Reer R, Braumann KM (2015) Video raster stereography back shape reconstruction: A reliability study for sagittal, frontal, and transversal plane parameters. Eur Spine J 24: 262-269.

31. Schulein S, Mendoza S, Malzkorn R, Harms J, Skwara A (2013) Rasterstereographic evaluation of interobserver and intraobserver reliability in postsurgical adolescent idiopathic scoliosis patients. J Spinal Disord Tech 2013: 143-149.

32. Mohokum M, Schulein S, Skwara A (2015) The Validity of Rasterstereography: A Systematic Review. Orthop Rev 7: 5899.

33. Knott P, Sturm P, Lonner B, Cahill P, Betsch M, et al. (2016) Multicenter comparison of $3 \mathrm{D}$ spinal measurements using surface topography with those from conventional radiography. Spine Deform 4: 98-103.

34. Liljenqvist U, Halm H, Hierholzer E, Drerup B, Weiland M (1998) The threedimensional surface measurement of spinal deformities using ideoraster stereography. Z Orthop Ihre Grenzgeb 136: 57-64.

35. Gabell A, Simons MA, Nayak US (1985) Falls in the healthy elderly: Predisposing causes. Ergonomics 28: 965-975.

36. Menant JC, Steele JR, Menz HB, Munro BJ, Lord SR (2008) Optimizing footwear for older people at risk of falls. J Rehabil Res Dev 45: 1167-1181.

37. Basler HD (2011) Acute pain therapy in paediatrics and geriatrics - pain measurement: Which pain scale in which patients? Anesthesiol Intensivmed Notfallmed Schmerzther 46: 334-342.

38. Butler D, Trafimow JH, Andersson GB, McNeill TW, Huckman MS (1990) Discs degenerate before facets. Spine 15: 111-113.

39. Yamamoto J, Bergstrom J, Davis A, Wing D, Schousboe JT, et al. (2017) Trunk lean mass and its association with 4 different measures of thoracic kyphosis in older community dwelling persons. PLoS One 12: e 0174710

40. Eguchi Y, Suzuki M, Yamanaka H, Tamai H, Kobayashi T, et al. (2017) Associations between sarcopenia and degenerative lumbar scoliosis in older women. Scoliosis Spinal Disord 12: 1-9.

41. Hapsari VD, Xiong S (2016) Effects of high heeled shoes wearing experience and hee height on human standing balance and functional mobility. Ergonomics 59: 249-264

42. Hong WH, Lee YH, Chen HC, Pei YC, Wu CY (2005) Influence of heel height and shoe insert on comfort perception and biomechanical performance of young female adults during walking. Foot Ankle Int 26: 1042-1048.

43. Menz HB, Roddy E, Marshall M, Thomas MJ, Rathod T, et al. (2016) Epidemiology of shoe wearing patterns over time in older women: associations with foot pain and hallux valgus. J Gerontol A Biol Sci Med Sci 71: 1682-1687.

44. Barnish MS, Barnish J (2016) High-heeled shoes and musculoskeletal injuries: A narrative systematic review. BMJ Open 6: $\mathrm{e} 010053$.

Copyright: (C2019 Schröder G. This is an open-access article distributed under the terms of the Creative Commons Attribution License, which permits unrestricted use, distribution, and reproduction in any medium, provided the original author and source are credited. 